\title{
LONG-TERM RESULTS OF CORNEAL WEDGE EXCISION FOR PELLUCID MARGINAL DEGENERATION
}

\author{
HUNTER MacLEAN, LYON P. ROBINSON and ALFRED W. WECHSLER \\ Sydney, Australia
}

\begin{abstract}
SUMMARY
Purpose: A retrospective study reporting long-term visual and astigmatic results of patients with pellucid marginal degeneration (PMD) treated by corneal wedge excision.

Methods: The notes of 9 patients (10 eyes) treated by corneal wedge excision were reviewed. All patients had typical PMD and were treated by excision of an inferior crescent of diseased corneal tissue. The excised area measured approximately $2 \mathrm{~mm}$ in width and extended from the 4 .o'clock to the 8 o'clock meridian. All thinned corneal tissue was removed. Normal-thickness corneal stroma was then reapposed with $10 / 0$ nylon or 10/0 polypropylene sutures. Post-operative selective suture removal was performed until a satisfactory visual and astigmatic result was achieved. This was guided by refraction, keratometry and photo-keratoscopy results. Pre-operative best corrected visual acuity ranged from $6 / 12$ to $6 / 60$ with an associated mean keratometric astigmatism of $+\mathbf{1 3 . 8}$ dioptres (range 8-25 dioptres, axis range $30^{\circ}-175^{\circ}$ ). Mean follow-up was 59 months (range 14-138 months).
\end{abstract}

Results: Post-operatively a stable corrected visual acuity of $6 / 9$ or better was achieved in all cases in a mean time of 5.4 months (range 3-12 months). Mean post-operative keratometric astigmatism was 1.4 dioptres (range 0.5-4 dioptres). Over the course of follow-up long-term astigmatic drift (LTAD) was noted, mean 2.1 dioptres (range 0.5-5.5 dioptres). Three patients developed mild inferior pannus related to peripherally sited sutures. One case developed apparent corneal hydrops within the corneal wound after 9 years of follow-up.

Conclusions: We believe that corneal wedge excision offers an excellent surgical result for patients with

From: Sydney Eye Hospital, Sydney, Australia.

Correspondence to: Hunter MacLean, Department of Ophthalmology, Royal Victoria Infirmary, Queen Victoria Road, Newcastle upon Tyne NE1 4LP, UK. Tel: +44(0191) 227 5065. Fax: +44(0191) 2275246.
PMD, although modification of the technique may be required to improve long-term astigmatic drift.

Pellucid marginal degeneration (PMD) is a progressive non-inflammatory corneal ectasia characterised by an area of inferior corneal thinning extending from the 4 o'clock to the 8 o'clock meridian. The area of thinning is crescent shaped and usually measures 1-2 mm in width and is found 1-2 mm from the inferior limbus (Fig. 1A). ${ }^{1}$ Males and females are equally affected. Rarely, PMD may coexist with keratoconus in the same eye, and they both share systemic associations such as atopy. ${ }^{2}$ In moderate to advanced cases normal cornea protrudes above the area of thinning (Fig. 1B), flattening the vertical meridian and producing large degrees of against-the-rule astigmatism (plus cylinder). Photo-keratoscopy and video-keratography are typical of the condition (Fig. 1C, D) and can differentiate the disease from keratoconus. ${ }^{3}$ As the ectasia progresses spectacle correction becomes unsatisfactory and contact lenses become difficult to fit due to inferior decentration of the lens. ${ }^{2-5}$ The traditional surgical approach utilises large, eccentrically placed penetrating grafts, ${ }^{4}$ but other surgical techniques have been described and include lamellar crescentic resection, ${ }^{4}$ crescentic penetrating keratoplasty, ${ }^{6}$ epikeratoplasty ${ }^{7}$ and corneal wedge excision. ${ }^{8}$ However, most reports consist of isolated cases with limited follow-up.

\section{PATIENTS AND METHODS}

Ten eyes of 9 patients with typical changes of PMD underwent full-thickness wedge excision of the thinned area of cornea. All patients were followed up for a minimum of 1 year (range 14-138 months) The operations were performed by one of two surgeons (L.P.R. and A.W.W.). Two patients were women and 7 were men, with an age range at operation of 17-61 years (mean 45 years). Coexisting 

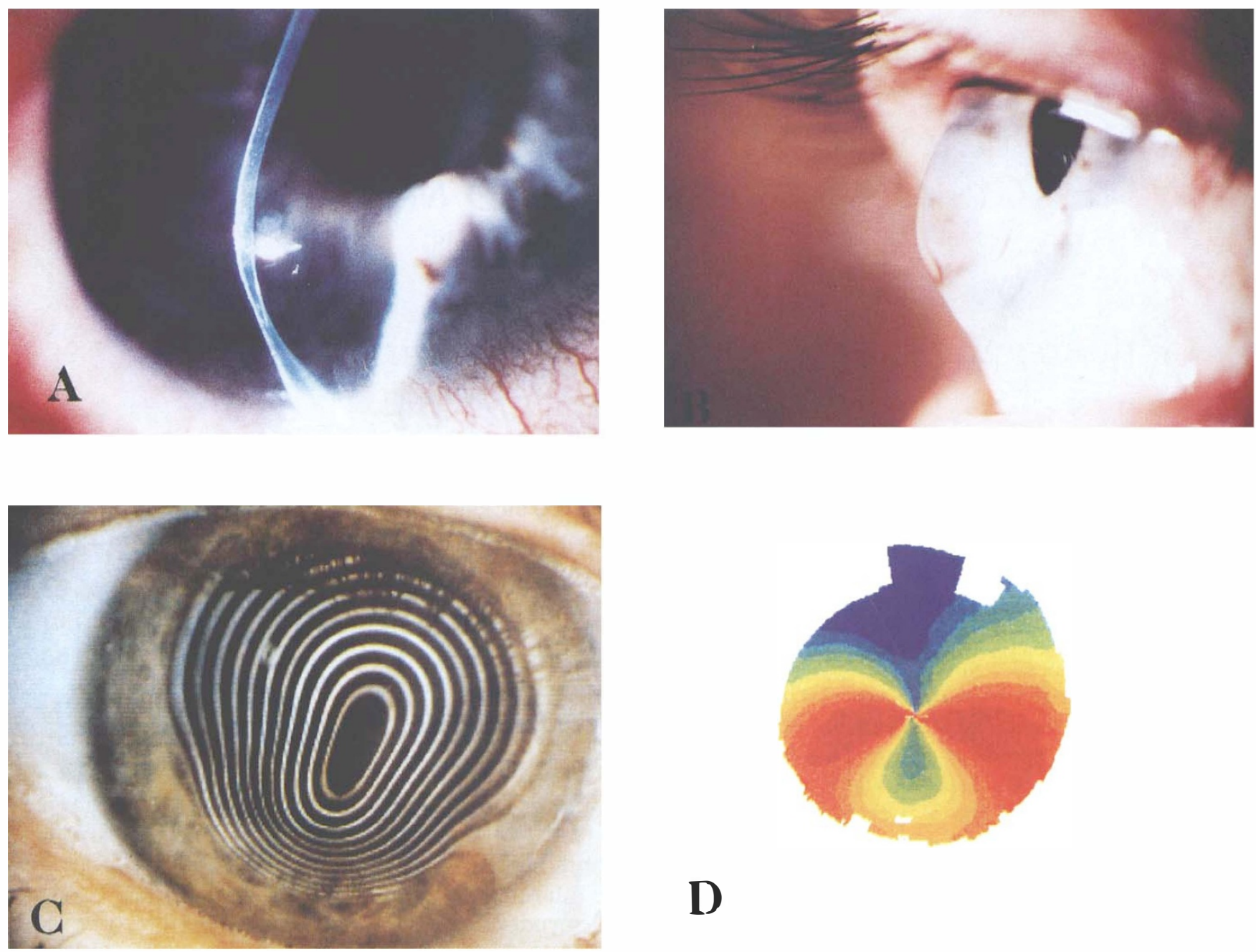

D

Fig. 1. (A) Slit beam showing thinned inferior stroma. (B) Lateral view of left eye showing bulging of the cornea above the thinned area. $(C)$ Typical photo-keratoscopic image of advanced pellucid marginal degeneration (PMD). Note the tightly packed inferior mires with elongation of central mires, representing high astigmatism (17 dioptres in this case). (D) Typical video-keratography of moderately advanced PMD displaying a 'teardrop' pattern representing marked steepening of the inferior cornea. Keratometric astigmatism measured 8 dioptres against-the-rule in this case.

systemic conditions included 2 patients with atopic dermatitis and 1 patient with asthma. All patients had moderate to advanced PMD with best corrected visual acuities of $6 / 12$ to $6 / 60$. Spectacle correction was unsatisfactory in all patients due to high astigmatism. Contact lenses proved impossible to fit because of inferior decentration. Mean pre-operative keratometric astigmatism was 13.8 dioptres (range $8-25$ dioptres, with axis range $30^{\circ}-175^{\circ}$ ). There were no features of coexisting corneal disease in any of the patients. Astigmatic change representing long-term astigmatic drift (LTAD) over the course of follow-up was calculated using vector analysis and vector decomposition. ${ }^{9,10}$

\section{Surgical Technique}

Bridle sutures were placed beneath the inferior and superior recti. An inferior crescentic corneal wedge approximately $2 \mathrm{~mm}$ wide was outlined from the 4 o'clock to the 8 o'clock meridian that included all areas of thin cornea. A paracentesis was fashioned and the anterior chamber deepened with viscoelastic. The corneal incisions were then deepened until penetration into the anterior chamber occurred. The outlined wedge of cornea was then excised with fine scissors. Between 10 and 15 10/0 nylon or 10/0 polypropylene sutures were placed, reapposing normal-thickness cornea (Fig. 2A, B). Slip knots were used and the tension adjusted until overcorrection of pre-operative astigmatism as judged by hand-held keratometry was achieved. Thus a typical immediate post-operative result would be +10 dioptres, axis $90^{\circ}$.

Post-operatively the patients were treated with topical corticosteroids and antibiotic eyedrops for approximately 1 month. Selective suture remove was 

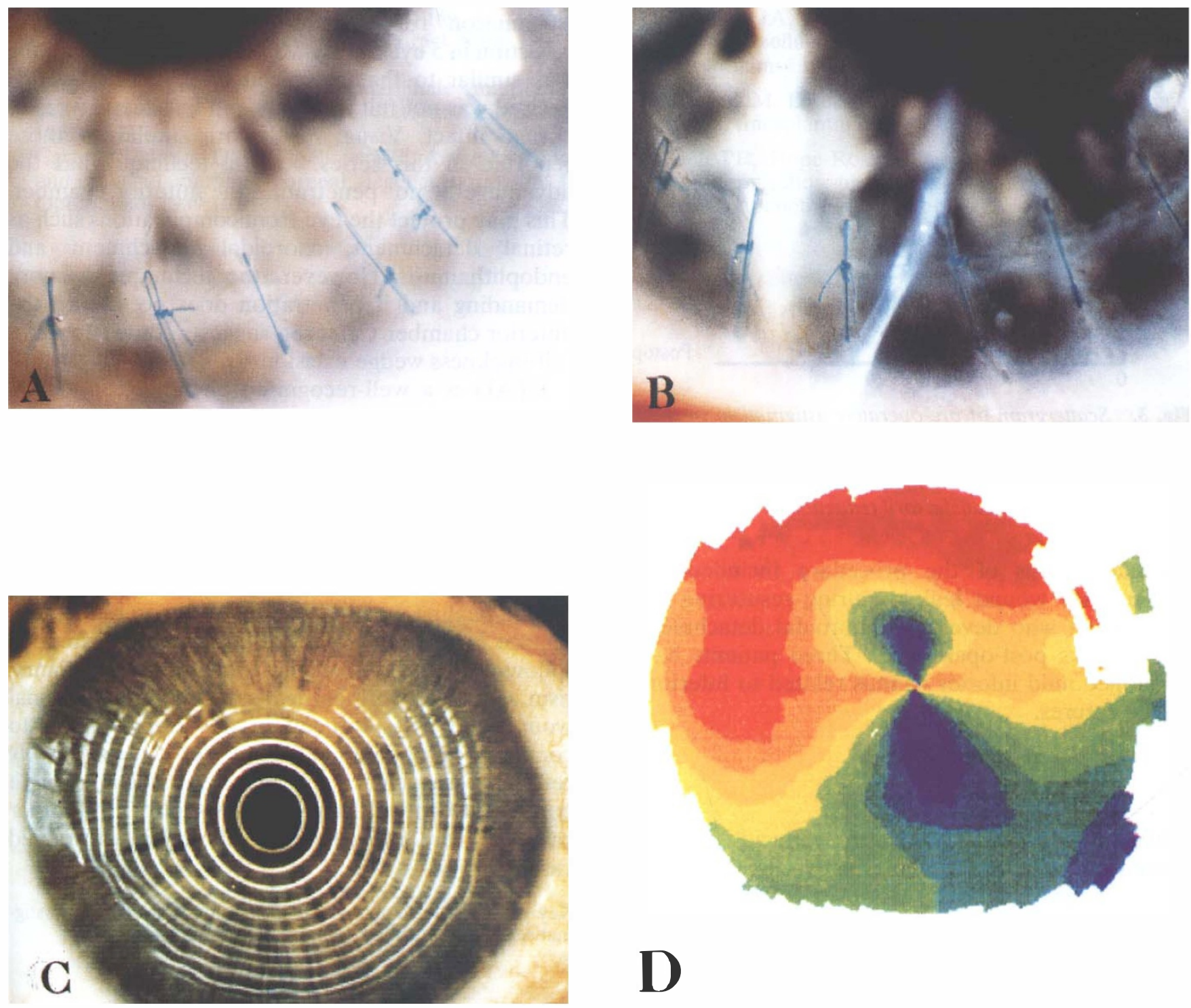

Fig.

2. (A) $10 / 0$ interrupted polypropylene sutures in an inferior crescent wound after wedge excision. (B) Slit beam showing normal-thickness stroma reapposed. (C) Photo-keratoscopy of a typical post-operative result. While inferior mires over the wound site are distorted, central mires are regular and nearly circular. Keratometric astigmatism post-operatively was 4 dioptres at $12^{\circ}$ compared with 13 dioptres at $15^{\circ}$ pre-operatively. (D) Video-keratography of the same patient shown in $C$.

begun at 3 months if excessive astigmatism was still present in the vertical meridian. This was guided by photo-keratoscopy, refraction and keratometry. All loose and broken sutures were removed. Sutures were no longer removed once the desired visual and astigmatic results were obtained. Fig. $2 \mathrm{C}$ and D demonstrate restoration of more normal central corneal shape after this endpoint had been achieved.

\section{RESULTS}

All patients achieved vision of $6 / 9$ or better with spectacle correction following the operation. Once consecutive stable refractions were measured spectacles were prescribed; this occurred in a mean time of 5.4 months post-operatively (range 3-12 months). Mean keratometric astigmatism at this time was 1.4 dioptres (range $0.5-4$ dioptres). Individual results are summarised in Fig. 3. Over the period of follow-up there has been significant LTAD. By vector analysis mean LTAD was calculated to be 2.1 dioptres (range 0.5-5.5 dioptres). Vector decomposition $^{9,10}$ of these figures reveals an axis shift of this astigmatism towards against-the-rule.

One patient was lost to follow-up 3 years after a successful operation but re-presented 9 years postoperatively with decreased visual acuity. Refraction was $-10,+12$ at $165^{\circ}$ and examination showed corneal oedema suggestive of hydrops at the original wound site. 


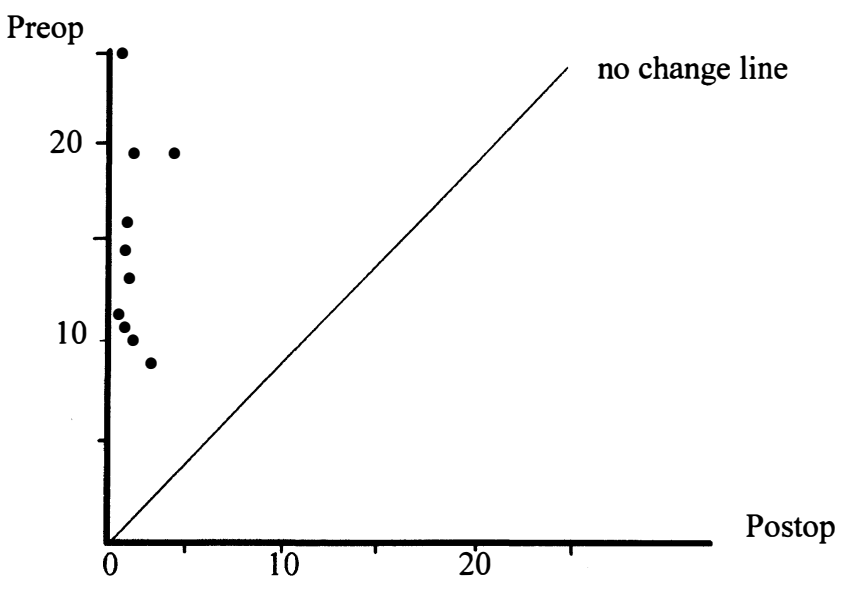

Fig. 3. Scattergram of pre-operative astigmatism in dioptres (mean 13.8 dioptres) plotted against post-operative astigmatism in dioptres (mean 1.4 dioptres). The slope shown in the graph represents the line of no change. All patients demonstrate satisfactory reduction in astigmatism.

Complications of the procedure included one patient with wound leak requiring resuturing and one patient who developed choroidal detachments for 3 weeks post-operatively. Three patients have developed mild inferior pannus related to inferiorly placed sutures.

\section{DISCUSSION}

Schlaeppi ${ }^{11}$ first used the term 'pellucid' meaning translucent to describe inferior corneal thinning without inflammation. However, scarring can develop as a result of corneal hydrops. ${ }^{1,11}$ Typically PMD involves the inferior quadrant but some patients have coexisting separate zones of central corneal thinning ${ }^{2,4}$ and rarely superior corneal thinning. ${ }^{13}$ Pre-operative assessment of patients with PMD should include examination of the central and superior cornea to exclude a second area of thinning. In these cases a large-diameter penetrating keratoplasty would be the most appropriate surgical option. However, in most cases corneal wedge excision offers several advantages over penetrating keratoplasty. First, surgical treatment is localised to the area of disease, making a smaller and stronger wound compared with the $360^{\circ}$ wound in penetrating keratoplasty. Most importantly, however, no donor tissue is used and thus graft rejection, primary graft failure and transmission of donor/host disease ${ }^{14}$ are all avoided. This is a significant advantage as graft rejection is markedly higher in grafts performed for PMD, presumably due to the proximity of the donor button to the limbus. Varley et al..$^{5}$ report rejection rates of $67 \%$, which compares poorly with the low rates generally reported for penetrating keratoplasty in keratoconus. Complications associated with longterm corticosteroids such as glaucoma are also avoided.
Cameron $^{4}$ reported results of lamellar crescentic resection in 5 eyes with PMD. The surgical technique was similar to that described here but the wedge excised was not full thickness and left deep layers of cornea intact. Visual results are similar to those reported in this series but the technique has the advantage of not penetrating the anterior chamber. This may protect the eye from complications such as retinal detachment, choroidal detachment and endophthalmitis. However, the technique is more demanding and if penetration does occur into the anterior chamber Cameron suggests conversion to a full-thickness wedge excision.

LTAD is a well-recognised phenomenon associated with corneal cataract wounds as well as penetrating keratoplasty. Chell et al. ${ }^{15}$ in their study of LTAD in corneal grafts found a mean astigmatic drift of 1.25 dioptres (range 0-5.5 dioptres), which compares reasonably with that found in this study. The use of more durable suture material or possibly later removal of corneal sutures to allow better wound healing may be required to try to reduce this feature in future cases. One patient after extended follow-up reverted to high against-the-rule astigmatism associated with corneal swelling at the original wound site. It is difficult in this isolated case to comment on possible aetiology, but it may possibly reflect a recurrence of disease associated with corneal hydrops. Longer follow-up of the other cases will reveal whether this will remain an isolated case.

Key words: Pellucid marginal degeneration, Keratoconus, Astigmatism, Wedge excision, Penetrating keratoplasty.

\section{REFERENCES}

1. Krachner JH. Pellucid marginal corneal degenerations. Arch Ophthalmol 1978;96:1217-8.

2. Kayazawa F, Nishimura K, Kodama Y, Tsuji T, Itoi M. Keratoconus with pellucid marginal corneal degeneration. Arch Ophthalmol 1984;102:895-900.

3. Maguire LJ, Klyce SD, MacDonald MB, Kaufman AG. Corneal topography and pellucid marginal corneal degeneration. Ophthalmology 1987;94:519-24.

4. Cameron JA. Results of lamellar crescentic resection for pellucid marginal corneal degeneration. Am J Ophthalmol 1992;113:296-302.

5. Varley GA, Macsai MS, Krachner JH. The results of penetrating keratoplasty for pellucid marginal corneal degeneration. Äm J Ophthalmol 1991;110:149-53.

6. Schanzlin DJ, Sarno EM, Robin BJ. Crescentic lamellar keratoplasty for pellucid marginal degeneration. Am J Ophthalmol 1983;96:253-4.

7. Fronterre A, Portesani GP. Epikeratoplasty for pellucid marginal corneal degenerations. Cornea 1991;10:450-3.

8. Dubroff S. Pellucid marginal corneal degenerations: report on corrective surgery. J Cataract Refract Surg 1989;15:89-93.

9. Dam-Johnson M, Alson T, Theodawson F. The longterm course of surgically induced astigmatism after a scleral tunnel incision. Eur J Implant Ref Surg 1994;6:337-43. 
10. Alson T, Dam-Johnson M. Evaluating surgically induced astigmatism. J Cataract Refract Surg 1994; 20:517-22.

11. Schlaeppi V. La dystrophie marginale inférieure pellucide de la cornée. Probl Actuels Ophtalmol 1957;1:672-4.

12. Carter JB, Jones DB, Wilhelmus KR. Acute hydrops and pellucid marginal corneal degeneration. Am J Ophthalmol 1989;107:167-9.
13. Cameron JA, Makmood MA. Superior corneal thinning with pellucid marginal corneal degeneration. Am J Ophthalmol 1990;109:486-7.

14. O'Day DM. Diseases potentially transmitted through corneal transplantation. Ophthalmology 1989;96:133-6.

15. Chell PB, Hope-Ross MW, Shah P, McDonnell PJ. Long-term follow-up of a single continuous adjustable suture in penetrating keratoplasty. Eye 1996;10:133-7. 